\title{
Research on Perceived Image of Beijing Night Tourism Based on Fuzzy Comprehensive Evaluation
}

\author{
Guangpu Chen ${ }^{1, *}$ and Bisha Tong ${ }^{2}$ \\ ${ }^{1,2}$ School of Economics and Management, Beijing Jiaotong University, China 100044 \\ *Corresponding author. Email: 19120727@bjtu.edu.cn
}

\begin{abstract}
Night tourism is gradually becoming a new model to promote the upgrading and development of tourism destinations. This paper constructs an index system for Beijing night tourism perception image based on literature analysis, collects tourist perception data through questionnaire survey, and analyzes Beijing night tourism perception image using fuzzy comprehensive evaluation method. The research results are as follows: (1) Tourists have a good overall perception of Beijing's night tourism image; (2) The satisfaction of "emotional image" and "overall image" is relatively high; "shopping", "infrastructure" and "catering" have reached the general level of satisfaction. "Night lighting", "leisure tourism activities" and "traffic" are less satisfied, which is mainly reflected in the inconspicuous theme features and poor coordination with the environment in night lighting, fewer types and inconspicuous cultural features in leisure tourism activities, as well as inconvenience and chaos in traffic. Finally, some suggestions are put forward for the development of night tourism in Beijing.
\end{abstract}

Keywords: Night tourism, Perceived image, Fuzzy comprehensive evaluation, Beijing.

\section{INTRODUCTION}

Night tourism caters to the living habits of modern people, shows tourists a new scene different from the daytime, and greatly improves the traditional tourism mode. At the same time, the development of night tourism prolongs the stay time of tourists, increases their consumption opportunities, and promotes the effective utilization of various resources, so as to promote the linkage development of tourism industry. Domestic research on night tourism began in the early 21 st century. Deng Yongyong et al. (2011) first made a research review on night tourism, defined the concept of night tourism, and summarized the relevant content of night tourism products in China in the past 10 years [1]. On the whole, the research scope of night tourism in China is relatively small, focusing more on the current situation of night tourism products and development strategies [2], and focus on descriptive research [3].

Tourism image is a synthesis of tourists' experience perception and emotional evaluation of various elements of tourist destinations [4]. Tourism image is not only a key factor to attract tourists, but also plays an important role in the development of tourist destinations [5]. In recent years, Beijing has put forward relevant countermeasures to promote the development of night tourism. However, from the perspective of overall development, there are still some problems in Beijing night tourism. Therefore, it is of great significance to analyze the image of Beijing night tourism. This article is based on the construction of Beijing night tourism image index system, using fuzzy comprehensive evaluation method to analyze the image of Beijing night tourism, and put forward suggestions for the development of Beijing night tourism.

\section{RESEARCH DESIGN}

\subsection{Index System}

Tourists' perception of tourism image is usually composed of multiple factors. Constructing a framework of tourism perception image index is an important foundation and premise for studying tourism perception image. This paper is based on the "cognition-emotion-whole" three-dimensional structure model. Among them, the cognitive image is based on the six elements of tourism, referring to relevant literature, and combining the characteristics of Beijing night tourism to obtain 6 first-level indicators and 23 second-level indicators. The measurement of emotional image refers to Su Yiwei's (2018) research results on 
the perceived image of tourism destinations in Beijing, and 5 second-level indicators are obtained ${ }^{[6]}$. Five second-level indicators are set up to measure tourists' satisfaction with the overall impression of Beijing night tourism. In summary, Beijing's night tourism perception image index system includes 8 first-level indicators and 33 second-level indicators (Table 1).

\subsection{Questionnaire Design and Data Collection}

In this paper, the survey of Beijing night tourism perception image is conducted by questionnaire survey. The questionnaire is divided into two parts: the first part is the basic information of tourists, and the second part is the tourists' perception of Beijing's night tourism image. The questionnaire items were designed with the five-level Likert scale. The questionnaire was distributed offline and online. The off-line survey site selected Beijing night tourism typical places, taking Wangfujing as an example, 26 questionnaires were collected offline and 47 questionnaires were collected online. A total of 73 samples were obtained, 4 invalid questionnaires were excluded, and 69 valid questionnaires were collected.

In order to ensure the scientificity of the questionnaire, the most commonly used Alpha coefficient is used to analyze the reliability of each indicator. The result shows that the Alpha coefficient is 0.943 , and the reliability coefficient values are greater than 0.70 , indicating that the reliability is good. Secondly, paired sample t-test was conducted on the above indicators. The purpose of the sample t-test is to compare the mean difference of the factors and test whether the factors are homogenous. The result shows that there are significant differences among the indicators.

\subsection{Research Method}

Fuzzy comprehensive evaluation method is a comprehensive evaluation method based on fuzzy mathematics. The comprehensive evaluation method transforms qualitative evaluation into quantitative evaluation based on the membership degree theory of fuzzy mathematics, that is, using fuzzy mathematics to make an overall evaluation of things or objects restricted by multiple factors. It has the characteristics of clear result and strong systematization. It can solve the fuzzy and difficult to quantify problems, and is suitable for the solution of various uncertain problems. This paper uses fuzzy comprehensive evaluation method to study the image of Beijing night tourism.

\section{ANALYSIS ON THE PERCEIVED IMAGE OF BEIJING NIGHT TOURISM}

\subsection{Perceived Image Evaluation Calculation Process}

According to the construction method of the fuzzy comprehensive evaluation model, combined with the data collected by the questionnaire, the fuzzy comprehensive evaluation of the perceived image of Beijing night tourism was calculated. The calculation process are as follows:

(1) Set up evaluation factor set and evaluation index set. Let $\mathrm{B}=\left(\mathrm{B}_{1}, \mathrm{~B}_{2}, \cdots, \mathrm{B}_{\mathrm{S}}\right)$ is the set of evaluation factors, $\mathrm{U}_{\mathrm{S}}=\left(\mathrm{U}_{1}^{\mathrm{S}}, \mathrm{U}^{\mathrm{S}}, \mathrm{U}^{\mathrm{S}} \mathrm{M}\right)$ is the evaluation index set.

(2) Establish a collection of indicators and comments. The questionnaire in this paper uses a five-level Likert scale, so the comment set is $\mathrm{V}=\left(\mathrm{V}_{1}\right.$, $\left.\mathrm{V}_{2}, \mathrm{~V}_{3}, \mathrm{~V}_{4}, \mathrm{~V}_{5}\right)=($ very dissatisfied, dissatisfied, neutral, satisfied, very satisfied $)=(1,2,3,4,5)$.

(3) Determine the weight of each evaluation index. The entropy method is used to calculate the index weight of Beijing night tourism perception image evaluation system. The weight of each index is shown in Table 1, and the weight vector $\boldsymbol{w}$ is constructed.

(4) Construct a fuzzy relationship matrix $\mathbf{R}=\left(\mathrm{r}_{\mathrm{ij}}\right)_{\mathrm{m} \times \mathrm{n}}$, where $r_{i j}$ is the membership degree of the evaluation index. Obtain the membership degree of Beijing night tourist perception image evaluation index (Table 2), and construct the fuzzy relationship matrix $\mathbf{R}$.

(5) Establish fuzzy operators for fuzzy comprehensive evaluation. Determine the fuzzy operator according to the index weight obtained in the first two steps and the fuzzy relationship matrix $\mathbf{R}$, $\mathrm{Z}_{\mathrm{i}}=w_{\mathrm{i}} \times \mathrm{r}_{\mathrm{i}}$, and construct the fuzzy number set $\mathrm{Z}$.

(6) Deblurring the index score. According to the formula $\mathrm{Q}=\mathrm{Z} \times \mathrm{V}$, the score of each index and the comprehensive score are calculated.

The calculation results show that the fuzzy comprehensive score of Beijing night tourism perception is 3.621, and the scores from T1 to T8 are $3.430,3.653,3.347,3.783,3.702,3.310,3.867$, and 3.811 respectively. 
Table 1. The perceived image index system of Beijing night tourism

\begin{tabular}{|c|c|c|c|}
\hline First-level indicator & $\begin{array}{c}\text { First-level indicator } \\
\text { weight }\end{array}$ & Second-level indicator & $\begin{array}{c}\text { Second-level } \\
\text { indicator weight }\end{array}$ \\
\hline \multirow{4}{*}{ T1 Night lighting } & \multirow{4}{*}{0.123} & T11 Bright & 0.285 \\
\hline & & T12 Beautiful & 0.222 \\
\hline & & T13 Integration with environment & 0.261 \\
\hline & & T14 Prominent theme & 0.232 \\
\hline \multirow{4}{*}{ T2 Catering } & \multirow{4}{*}{0.096} & T21 Rich variety & 0.251 \\
\hline & & T22 Moderate price & 0.230 \\
\hline & & T23 Outstanding local characteristics & 0.273 \\
\hline & & T24 Good hygiene condition & 0.246 \\
\hline \multirow{4}{*}{$\begin{array}{l}\text { T3 Leisure tourism } \\
\text { activities }\end{array}$} & \multirow{4}{*}{0.145} & T31 Rich variety & 0.218 \\
\hline & & T32 Moderate price & 0.229 \\
\hline & & T33 Outstanding local characteristics & 0.266 \\
\hline & & T34 Cultural & 0.287 \\
\hline \multirow{4}{*}{ T4 Shopping } & \multirow{4}{*}{0.098} & T41 Moderate price & 0.220 \\
\hline & & T42 Outstanding features & 0.253 \\
\hline & & T43 Good quality & 0.237 \\
\hline & & T44 Good environment & 0.290 \\
\hline \multirow{4}{*}{ T5 Infrastructure } & \multirow{4}{*}{0.126} & T51 Good sanitary condition & 0.234 \\
\hline & & T52 High security & 0.284 \\
\hline & & T53 Clear tourism identification system & 0.252 \\
\hline & & T54 Complete public facilities & 0.231 \\
\hline \multirow{3}{*}{ T6 Traffic } & \multirow{3}{*}{0.106} & T61 Convenient transportation & 0.362 \\
\hline & & T62 Smooth and orderly traffic & 0.330 \\
\hline & & T63 Traffic comfort & 0.308 \\
\hline \multirow{5}{*}{ T7 Emotional image } & \multirow{5}{*}{0.149} & T71 Bustling & 0.194 \\
\hline & & T72 Patriotism and national pride & 0.134 \\
\hline & & T73 Pleasant and relaxing & 0.177 \\
\hline & & T74 International pluralism & 0.249 \\
\hline & & T75 Rich cultural connotation & 0.245 \\
\hline \multirow{5}{*}{ T8 Overall image } & \multirow{5}{*}{0.157} & T81 Good overall image & 0.246 \\
\hline & & T82 Good service & 0.203 \\
\hline & & T83 Friendly attitude of residents & 0.132 \\
\hline & & T84 Operating hours of night tourist places & 0.186 \\
\hline & & T85 High reputation of night tourism & 0.233 \\
\hline
\end{tabular}

\subsection{Fuzzy Comprehensive Analysis}

\subsubsection{Analysis of Fuzzy Comprehensive Overall Score}

On the whole, the fuzzy comprehensive score of Beijing night tourism tourists' perception is 3.621, which indicates that tourists' perception of Beijing night tourism is generally good. According to relevant reports, the demand for night travel in Beijing ranks first in China, and the development level of Beijing's night tourism is higher than that of other regions. However, there is still a large space for improvement and development in the future.

\subsubsection{Fuzzy Comprehensive Analysis of First-level Indicator}

The comprehensive scores of "emotional image" and "overall image" are 3.867 and 3.811 respectively, which are at a relatively high level. Relying on its political and cultural center and the background of an international metropolis, Beijing has a profound cultural heritage and rich night tourism resources, attracting many tourists to come here, so tourists have a good overall perception of the emotional image and overall image of Beijing night tourism.

The comprehensive scores of "shopping", "infrastructure" and "catering" are 3.783, 3.702, and 3.653 respectively, which are at the average level. First of all, although some well-known shopping districts such as Wangfujing and Sanlitun have been formed in Beijing, some tourists believe that there are problems such as excessive shopping prices and lack of distinctive shopping features. Secondly, because night tourism in Beijing is still in the preliminary stage of development, the relevant infrastructure and supporting public services are relatively backward, which cannot fully meet the basic needs of tourists. In addition, experiencing food is also an important motivation for tourists to participate in night tourism activities. Tourists generally believe that there are more varieties of catering, but the high prices and poor sanitary conditions often make tourists dissatisfied.

The comprehensive scores of "night lighting", "leisure tourism activities" and "traffic" were 3.430, 3.347 , and 3.310 respectively, which are at a lowel. 
Due to the particularity of the unfolding time, night tourism activities have higher requirements for lighting. The reasons why tourists are less satisfied with the "night lighting" are that the lighting of some night tourist activities is not bright enough, which leads to the lack of security; the second is the poor coordination of lighting colors, styles and the surrounding environment, and the lighting theme features are not prominent. In addition, tourists believe that the richness of night tourism activities in Beijing still needs to be improved. At the same time, night tourism is an indispensable part of tourists' integration into the destination life. They hope to experience the local characteristic culture in the process of experiencing night tourism activities. Tourists have the lowest scores on the perception of "traffic", indicating that traffic conditions have become an important factor hindering the development of night tourism in Beijing, especially the convenience and orderliness of traffic urgently need to be improved.

\section{CONCLUSION AND SUGGESTIONS}

\subsection{Conclusion}

Based on previous research results, this paper constructs the index system of Beijing night tourism image, collects tourists' perception data through questionnaire survey, and analyzes Beijing night tourism image by fuzzy comprehensive evaluation method. According to the results, tourists have a good perception of Beijing's night tourism image. Specifically, the satisfaction of "emotional image" and "overall image" is relatively high and should be maintained in the future. Tourists are less satisfied with "night lights", "recreation activities" and "traffic". Among them, the theme of night lighting is not prominent and night lighting has poor coordination with the surrounding environment. The richness and cultural characteristics of leisure tourism activities cannot meet the needs of tourists. It is worth noting that the inconvenient and disorderly transportation of Beijing night tourism makes tourists feel very dissatisfied and urgently needs to be improved. In addition, "shopping", "infrastructure" and "catering" have reached the general level of satisfaction, which should also be concerned by government departments

Table 2. Index membership degree

\begin{tabular}{|c|c|c|c|c|c|c|}
\hline $\begin{array}{l}\text { First-level } \\
\text { indicator }\end{array}$ & $\begin{array}{l}\text { Second-level } \\
\text { indicator }\end{array}$ & Very satisfied & Satisfied & Neutral & Dissatisfied & $\begin{array}{c}\text { Very } \\
\text { dissatisfied }\end{array}$ \\
\hline \multirow{4}{*}{$\mathrm{T} 1$} & T11 & 0.188 & 0.377 & 0.304 & 0.130 & 0.001 \\
\hline & T12 & 0.159 & 0.333 & 0.406 & 0.101 & 0.001 \\
\hline & T13 & 0.116 & 0.217 & 0.435 & 0.203 & 0.029 \\
\hline & T14 & 0.145 & 0.261 & 0.406 & 0.174 & 0.014 \\
\hline \multirow{4}{*}{$\mathrm{T} 2$} & $\mathrm{~T} 21$ & 0.362 & 0.290 & 0.261 & 0.087 & 0.001 \\
\hline & $\mathrm{T} 22$ & 0.130 & 0.232 & 0.420 & 0.174 & 0.043 \\
\hline & $\mathrm{T} 23$ & 0.246 & 0.348 & 0.319 & 0.087 & 0.001 \\
\hline & T24 & 0.174 & 0.362 & 0.406 & 0.058 & 0.001 \\
\hline \multirow{4}{*}{ T3 } & T31 & 0.145 & 0.275 & 0.406 & 0.159 & 0.014 \\
\hline & T32 & 0.101 & 0.246 & 0.507 & 0.145 & 0.001 \\
\hline & T33 & 0.174 & 0.362 & 0.348 & 0.116 & 0.001 \\
\hline & T34 & 0.072 & 0.217 & 0.522 & 0.145 & 0.043 \\
\hline \multirow{4}{*}{$\mathrm{T} 4$} & $\mathrm{~T} 41$ & 0.217 & 0.362 & 0.333 & 0.072 & 0.014 \\
\hline & T42 & 0.246 & 0.333 & 0.304 & 0.116 & 0.001 \\
\hline & $\mathrm{T} 43$ & 0.275 & 0.377 & 0.290 & 0.058 & 0.001 \\
\hline & T44 & 0.217 & 0.478 & 0.232 & 0.072 & 0.001 \\
\hline \multirow{4}{*}{ T5 } & $\mathrm{T} 51$ & 0.261 & 0.319 & 0.304 & 0.101 & 0.014 \\
\hline & $\mathrm{T} 52$ & 0.174 & 0.377 & 0.377 & 0.072 & 0.001 \\
\hline & $\mathrm{T} 53$ & 0.275 & 0.333 & 0.275 & 0.101 & 0.014 \\
\hline & T54 & 0.261 & 0.290 & 0.333 & 0.116 & 0.001 \\
\hline \multirow{3}{*}{ T6 } & T61 & 0.130 & 0.261 & 0.377 & 0.203 & 0.029 \\
\hline & T62 & 0.087 & 0.188 & 0.464 & 0.217 & 0.043 \\
\hline & T63 & 0.174 & 0.362 & 0.391 & 0.072 & 0.001 \\
\hline \multirow{5}{*}{$\mathrm{T} 7$} & $\mathrm{~T} 71$ & 0.362 & 0.319 & 0.275 & 0.043 & 0.001 \\
\hline & $\mathrm{T} 72$ & 0.188 & 0.333 & 0.377 & 0.087 & 0.014 \\
\hline & $\mathrm{T} 73$ & 0.333 & 0.348 & 0.232 & 0.058 & 0.029 \\
\hline & $\mathrm{T} 74$ & 0.391 & 0.304 & 0.304 & 0.001 & 0.001 \\
\hline & $\mathrm{T} 75$ & 0.261 & 0.275 & 0.348 & 0.101 & 0.014 \\
\hline \multirow{5}{*}{$\mathrm{T} 8$} & $\mathrm{~T} 81$ & 0.290 & 0.406 & 0.261 & 0.043 & 0.001 \\
\hline & T82 & 0.333 & 0.290 & 0.261 & 0.087 & 0.029 \\
\hline & T83 & 0.188 & 0.377 & 0.391 & 0.043 & 0.001 \\
\hline & T84 & 0.217 & 0.246 & 0.391 & 0.116 & 0.029 \\
\hline & $\mathrm{T} 85$ & 0.377 & 0.290 & 0.261 & 0.072 & 0.001 \\
\hline
\end{tabular}




\subsection{Suggestions}

First, create unique night lighting. The lighting of the scenic spot should follow the principles of urban lighting construction, combined with the characteristics of the scenic spot, and comprehensively consider the color, lamp material, and lamp shape, so that the night tourism lighting can be integrated with the environment. In addition, the theme of night lighting should be prominent, reflecting the local characteristics.

Second, enrich night tourism activities. Beijing should enrich the local night tourism resources and innovate night tourism activities according to its own characteristics and urban tourism image positioning. At the same time, the flexible adjustment of the business hours of tourism places can meet the needs of tourists to obtain more abundant tourism experience in limited time.

Third, improve the traffic environment for night tourism. Traffic safety and smooth traffic are common problems in tourism. For night tourism, these problems are more prominent and acute. Especially during the peak period of commuting and traffic flow, the transportation department should strictly investigate violations of traffic rules and regulations, and regulate the behavior of drivers and pedestrians. In addition, special tourist trains and through train lines in scenic spots will be added to enhance the accessibility of night tourist places and realize the integration of transportation and travel.

\section{REFERENCES}

[1] Deng yongyong, Guo wen. Research Overview of Domestic Night Tourism Product[J]. Guangdong Agricultural Sciences, 2011, 38(20): 150-152.

[2] Wen tong. Research on Urban Night Tourism Products[J]. Urban Problems, 2007(08): 42-45.

[3] Sheng qiaoling. Research on Upgrading of Night Tourism in Chongqing Based on Supply Side SWOT Analysis[J]. Tourism Overview, 2019(10): 96-97.

[4] Li xi, Ye sheng, Wang dong. Non-structured Measurement of Perceived Image in Tourism Destinations_-Taking Perceived Features of Macau Business Tourists as A Case $[\mathrm{J}]$. Tourism Tribune, 2011 ,26(12): 57-63.

[5] Huang zhenfang, Li xiang. On the Image Perception and Promotion Pattern of Tourist Destination[J]. Tourism Tribune, 2002(03): 65-70.

[6] Su yiwei, Research on the Perceived Image of Tourist Destination in Beijing Based on Text Mining[D]. Yanshan University, 2018. 